\title{
Fracture of the lateral process of the talus: computed tomographic scan diagnosis
}

\author{
Jonathan Noble MB, ChM, FRCS, FRCS(Ed) and Stephen G. Royle MB, ChB, FRCS(Ed) \\ Department of Orthopaedic Surgery, University of Manchester, Hope Hospital, Salford, UK
}

\begin{abstract}
Fracture of the lateral process of the talus is rare but can be mistaken for a simple ankle sprain ${ }^{1}$. A case with normal conventional radiographs is presented to draw attention to this diagnosis in the resistant ankle sprain, and to highlight some of the problems that may be encountered with treatment.
\end{abstract}

Keywords: Talus, stress fracture, computed tomographic scan

\section{Case report}

A 20-year-old professional footballer presented with a painful ankle on exertion after a twisting injury a few weeks earlier. Clinical examination revealed only minor tenderness over the anterolateral part of the ankle joint. Conventional radiographs, tomograms and a computed tomographic (CT) scan at this stage were normal, but a skeletal scintigram showed an area of increased uptake in the inferolateral talus, adjacent to the subtalar joint (Figure 1).

In view of persistent symptoms despite conventional treatment, a second CT scan was performed which showed a fracture of the lateral process of the talus extending into the subtalar joint (Figure 2).

A period in plaster failed to improve the situation and an ankle arthroscopy was performed. This showed no abnormality apart from a small notch in the articular surface of the inferolateral part of the talus.

Despite some initial improvement, the patient's symptoms relapsed while training. Plain radiographs were again normal, but a further CT scan showed an unequivocal fracture with surrounding sclerosis (Figure 3). A diagnosis of non-union was made.

An operative approach through an anterolateral reversed hockey stick incision was performed. No abnormality could be found in the articular surface and drilling across the site of the fracture was performed.

A relapse of symptoms occurred on the resumption of training 4 months later and a sclerotic area became visible on plain radiographs.

A second operative procedure was performed with exposure of the fracture, which was curetted, and a cancellous bone graft from the distal tibia was packed into the defect. The fractured lateral tuberosity was fixed internally with a Herbert screw. A period of 12 weeks in plaster ensued.

The patient made a steady recovery, and returned to top level competitive professional football 2 years after his original injury.

\section{Discussion}

Fractures of the lateral process of the talus are rare, and may be overlooked as symptoms are similar to an inversion ankle sprain, and may account for up to $1 \%$ of these injuries ${ }^{2}$. These fractures have been divided into three types: (1) The simple fracture extending from the ankle to the subtalar joint; (2) The comminuted fracture; and (3) The chip fracture into the subtalar joint, as in the case reported here.

Figure 1. Scintigram showing increased uptake around the lateral talus

Address for correspondence: Mr S. G. Royle, Herries Cottage,

Aspenshaw, Birch Vale, Stockport, Cheshire SK12 5AU, UK 


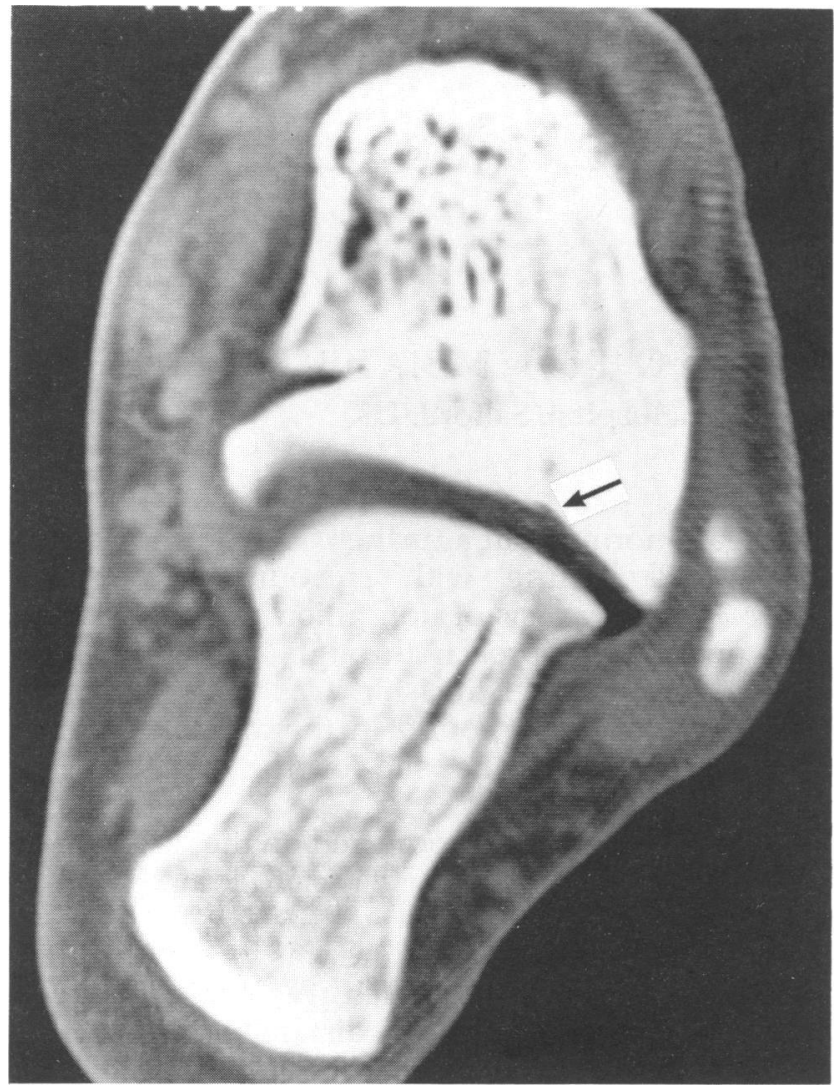

Figure 2. CT scan showing fracture line in the lateral talus (arrow)

Union of undisplaced fractures can usually be anticipated with conservative treatment, but nonunion can occur, particularly in displaced fractures ${ }^{1}$.
Early operative treatment of displaced or comminuted fractures in the form of fixation or excision is recommended ${ }^{2}$. Problems with the subtalar joint in the long term are not infrequent in comminuted or displaced fractures, and subtalar arthrodesis may be required ${ }^{3}$.

The case presented here highlights two of the main problems encountered when treating fractures of the lateral process of the talus.

First, the diagnosis may be difficult to make and the radiographs may be normal. We recommend that both skeletal scintigraphy and CT scanning should be used in the resistant ankle sprain. The presence of normal radiographs creates difficulty assessing the progress of the fracture.

Second, obtaining union can be a problem in these fractures and surgical intervention with bone grafting and internal fixation may be required.

\section{Acknowledgements}

Many people helped and advised in the management of this difficult case. We are grateful to all of them, particularly to the orthopaedic surgeons Dr Roger Mann and Professor Lesley Klenerman, and to the Radiologists Dr J. J. K. Brown, Dr St Clair Forbes and $\mathrm{Dr} \mathrm{H}$. Mantora. We are also grateful to Manchester United Football Club who unswervingly supported the player and doctors throughout this difficult case.

\section{References}

1 Heckman JD. Fractures and dislocations of the foot. In: Rockwood CA, Green DP, eds. Fractures in Adults, Vol. 2. 2nd edn. Philadelphia: JB Lippincott, 1984: 1720-3.

2 Mukherjee SK, Pringle RM, Baxter AD. Fracture of the lateral process of the talus. A report of thirteen cases. J Bone Joint Surg [Br] 1974; 56-B: 263-73.

3 Hawkins LG. Fractures of the lateral process of the talus. J Bone Joint Surg [Am] 1965; 47-A: 1170-5.

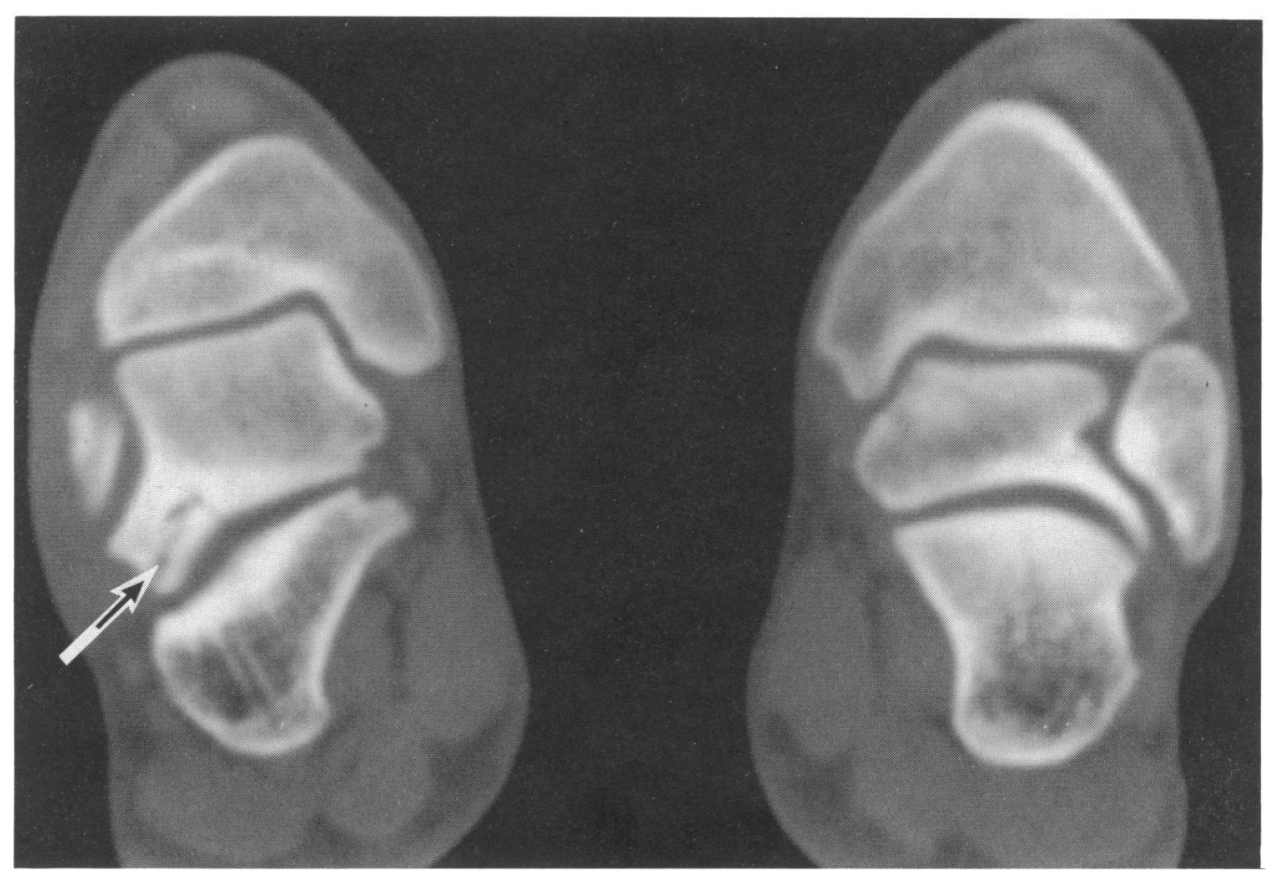

Figure 3. CT scan showing fragmentation and sclerosis of the talar fracture suggesting non-union (arrow) 